\title{
Livro de apoio para professor iniciante do município do Rio de Janeiro: clarificando concepções
}

\author{
Sandro Tiago Figueira* \\ Fundação Oswaldo Cruz \\ Helena Amaral Fontoura** \\ Universidade do Estado do Rio de Janeiro
}

Resumo Concebendo que perspectivas teóricas e concepções de ensinar e aprender integram os materiais de apoio direcionados aos professores iniciantes, tomamos no presente artigo o objetivo clarificar as concepções e princípios do trabalho pedagógico que ancoram o livro "Aula nota 10". O percurso analítico baseou-se na tematização onde procuramos os núcleos de sentido que focalizassem as visões de professor, do processo de ensino-aprendizagem e dos referentes formativos. A partir da conjugação dos resultados, concluímos que há a presença da concepção de professor distinguido entre aquele que executa e que pensa. Nesta perspectiva defendemos a necessidade de uma postura docente não aplicacionista, e sim crítica, para que possamos instrumentalizar os professores que se iniciam na profissão a tomarem suas próprias decisões, com conhecimento, competência e criatividade.

PALAVRAS-CHAVE: Formação de professores; Material de apoio; Ensino e aprendizagem. 


\section{Support book for the municipality of Rio de Janeiro beginner teacher: clarifying conceptions}

Abstract Conceiving that theoretical perspectives and concepts of teaching and learning are part of the support materials targeted at beginners, teachers take this article aimed to clarify the concepts and principles of pedagogical work that anchor the book "Class Note 10". The route was based on analytical study where we seek the nuclei of meaning that focusing the views of professor, teaching-learning process and related training. From the combination of the results, we conclude that there is the presence of design professor distinguished between that running and you think. In this respect we support the need for a teacher not aplicacionista, but critical, so that we can exploit the teachers who start in the profession to take their own decisions, with knowledge, skill and creativity.

KEYWORDS: Teacher education; Support material; Teaching and learning.

A realidade educacional brasileira possui características muito diversas e encontrar caminhos efetivos de ensino-aprendizagem adequados a essa diversidade tem sido um dos grandes desafios do campo da formação de professores. Configurando como um desses percursos tem-se a produção de materiais de apoio, tais como livros didáticos, paradidáticos, vídeos, entre outros, com o intuito de contribuir com a melhoria do trabalho docente.

Reconhecemos a importância desses materiais para a promoção de práticas pedagógicas comprometidas com aprendizagens satisfatórias, no entanto, estamos com Bizzo (2009), quando nos alerta para o fato de que os docentes não devem abdicar de sua autonomia, outorgando decisões suas aos materiais, pois cabe ao professor decidir qual é o mais adequado à sua realidade e de que forma podem ser utilizados.

Nesse sentido, concebendo que perspectivas teóricas e concepções de ensinar e aprender integram os materiais de apoio direcionados aos docentes e tomando o objetivo da presente pesquisa de investigar as dinâmicas formativas e estratégias metodológicas oferecidas aos professores iniciantes da Secretaria Municipal de Educação do Rio de Janeiro (SMERJ), debruçamo-nos na apresentação e análise do livro "Aula nota 10- quarenta e nove técnicas para ser um professor campeão de audiência" de Doug Lemov, buscando clarificar as concepções e princípios do trabalho pedagógico.

O livro é constituído por técnicas que, segundo Lemov (2011), foram elaboradas a partir das suas anotações das observações das aulas de professores eficazes. As técnicas estão divididas em duas partes, sendo denominadas técnicas essenciais na primeira parte, e na segunda, técnicas para ajudar os alunos a tirarem o máximo da leitura. 
A partir das duas partes, o autor organizou as técnicas em doze capítulos cujos títulos envolvem temas sobre expectativas acadêmicas e comportamentais, a estruturação das aulas e as dimensões presentes na cultura escolar, elencados de professores artesãos cuja atenção à técnica e a execução diferencia-os da maioria dos seus pares (LEMOV, 2011, p.22).

Apresentamos no quadro 1 a organização dos capítulos:

Quadro 1 - Lista dos capítulos do livro

\begin{tabular}{|l|l|l|}
\hline Capítulo & \multicolumn{1}{|c|}{ Título } & Número de páginas \\
\hline $\mathbf{1}$ & Criar altas expectativas acadêmicas & 28 \\
\hline $\mathbf{2}$ & Planejar para garantir um bom desempenho acadêmico & 13 \\
\hline $\mathbf{3}$ & Estruturar e dar aulas & 38 \\
\hline $\mathbf{4}$ & Motivar os alunos nas suas aulas & 33 \\
\hline $\mathbf{5}$ & Criar uma forte cultura escolar & 20 \\
\hline $\mathbf{6}$ & Estabelecer e manter altas expectativas de comportamento & 33 \\
\hline $\mathbf{7}$ & Construir valores e autoconfiança & 20 \\
\hline $\mathbf{8}$ & Melhorar seu ritmo & 9 \\
\hline $\mathbf{9}$ & Estimular os alunos a pensar criticamente & 10 \\
\hline $\mathbf{1 0}$ & Por que todos professores podem ser professores de leitura & 13 \\
\hline $\mathbf{1 1}$ & Ensinando decodificaçáo, vocabulário e fluência & 17 \\
\hline $\mathbf{1 2}$ & Compreensão: como ensinar alunos a entender o que leem & 27 \\
\hline
\end{tabular}

Fonte: Elaboração própria dos autores

Doug Lemov lecionou História e Inglês em seu início de carreira nos níveis fundamental, médio e superior, e atualmente ocupa o cargo de diretor-executivo de uma organização não governamental em Nova York. A produção do referido livro deu-se por meio dos registros escritos de suas observações em salas de aulas de professores que trabalham em bairros periféricos. De suas anotações, elaborou uma lista do que os professores faziam, focalizando especificamente nas 'técnicas que diferenciam os professores não dos ruins, mas daqueles que são apenas bons'.

O contexto de observação foram escolas americanas denominadas charter ${ }^{1}$, que são instituições públicas, porém de gestão privada, e sua presença nos Estados Unidos data desde os anos 90 e têm como missão eliminar a desigualdade no desempenho escolar. O parâmetro de desempenho dos alunos é tomado dos testes padronizados estaduais que incluem uma medida comparativa, a $\mathrm{SWA}^{2}$, que evidencia a média segundo a raça dos alunos.

Os professores estudados para a construção do livro pertenciam à instituição Uncommon Schools, uma escola charter em que Lemov foi diretor. Esses docentes eram por ele concebidos como profissionais que estão alinhados a métodos e técnicas de instrução. Para o autor, uma técnica é uma ação e quanto você mais praticar, melhor você ficará. 
Consideramos importante explorar o termo técnica com o intuito de melhor entender seu uso no campo da Educação. Em Garcia (2010) podemos perceber que o professor visto como um técnico eficaz surge nos anos 1960 sob a influência da perspectiva racionalista, em que este deveria atingir os objetivos de instrução através de uma série de meios e recursos. Já o modelo da racionalidade técnica, explicam Pesce e André (2012), enfatiza a dicotomia teoria-prática e por consequência a separação entre conhecimento específico e conhecimento aplicado, entre ciência e técnica e entre saberes e métodos, para mencionar algumas das dicotomias. Nesta perspectiva, a sala de aula se torna um espaço regulado por um sistema lógico infalível. Sob essa lógica percebemos a não consideração da imprevisibilidade que se faz presente nas mais variadas salas de aula. A realidade escolar é muito complexa, o que torna o pleno domínio desse espaço algo muito difícil de ser alcançado.

Garcia (2010) propõe a seguinte indagação sobre os docentes: seriam técnicos ou profissionais reflexivos? Com o intuito de fomentar a construção de respostas, sinaliza o autor que os bons docentes são tecnicamente competentes e capazes de refletir sobre os fins, os processos, os conteúdos e os resultados do seu trabalho. Reconhecemos, nessa perspectiva, os professores também como técnicos que entendem o processo de ensino-aprendizagem, que tomam a teoria como um dos sustentáculos de seu agir, uma vez que através dela, qualificam a prática e ao mesmo tempo ressignificam a teoria. Contribuindo com nossa reflexão, Fontoura, Pierro e Chaves (2011) ressaltam que a técnica fica na interseção entre o filosófico e científico, abrangendo, entre outros, a organização e os planos de ação docente. Dessa maneira, a dimensão técnica refere-se ao como educar, por que meios realizar concretamente a educação.

Lemov (2011), na introdução do livro distribuído aos docentes da SMERJ, apresenta uma justificativa quanto o uso do termo 'técnica', afirmando,

digo "técnicas" e não "estratégias" mesmo que a profissão do magistério tenda a usar a última expressão. Para mim, uma estratégia é uma abordagem generalista de problemas, um jeito de informar as decisões. Uma técnica é uma coisa que você pode dizer ou fazer de forma específica. (p.20)

Inferimos que uma técnica associada à despolitização e à descontextualização torna-se meramente tecnicista, como explicam Fontoura, Pierro e Chaves (2011), esvaziando assim o complexo processo de ensino-aprendizagem de suas dimensões filosóficas, humanas e sociais, encaminhando-o a uma dinâmica linear, quase como uma garantia de bons resultados a serem alcançados a partir de seu uso - 'use esta técnica que o resultado será alcançado’ -. Entendemos que a absorção de técnicas sem uma dinâmica reflexiva do seu uso, isto é, aceitando-a como um caminho prescritivo para alcance dos objetivos de ensino, enfraquece a dinâmica de ensino-aprendizagem esvaziando seu real sentido.

Zeichner (2008), analisando o conceito de reflexão, explica que a assunção do professor reflexivo vem num movimento contra a visão dos docentes enquanto técnicos que fazem o que outras pessoas, externamente à escola, querem que façam. Assim sendo, os professores passam a ser reconhecidos enquanto sujeitos que exercem um papel ativo no processo de formulação dos propósitos e finalidades de seu trabalho. 
Percebe-se que a apropriação de técnicas desarticulada do compromisso com os fins da educação, como também dos aspectos moral e ético, podem levar os professores a reduzirem sua prática pedagógica em ajustes de meios para atingir objetivos definidos por outros. Com vistas a superar tal redução, os docentes "devem agir com uma clareza política maior sobre quais interesses estão sendo privilegiados por meio de suas ações cotidianas”. (ZEICHNER, 2008, p.546)

Em busca dessa clareza, analisamos o livro em tela através de uma leitura atenta e diálogos teóricos empreendidos com Zeichner (2008), Fontoura, Pierro e Chaves (2011), André e Pesce (2012) e André (2015) buscando identificar a visão de professor, concepção de ensino-aprendizagem e os referentes formativos. O termo referente formativo foi desenvolvido por André (2015) e seu significado centra-se em aspectos que são considerados numa ação de formação.

Cada critério escolhido englobou focos para análise, conforme apresentamos no quadro 2 .

Quadro 2-Critérios adotados para análise

\begin{tabular}{|l|l|}
\hline \multicolumn{1}{|c|}{ Critério } & \multicolumn{1}{c|}{ Foco da análise } \\
\hline Visão de professor & $\begin{array}{l}\text { Autoritário, técnico, compreensivo, possuidor de saberes, } \\
\text { determinado historicamente. }\end{array}$ \\
\hline Concepçáo de ensino-aprendizagem & $\begin{array}{l}\text { Verbalista, de controle social, democrático, compartilhado, } \\
\text { a partir de necessidades concretas. }\end{array}$ \\
\hline Referentes formativos & $\begin{array}{l}\text { Presença de questốes transversais, proposiçóes curriculares e } \\
\text { dimensăo da prática docente. }\end{array}$ \\
\hline
\end{tabular}

Fonte: Elaboração própria dos autores

Os focos de análise assentam-se no quadro de abordagens pedagógicas elaborado por Fontoura, Pierro e Chaves (2011), uma vez que reconhecemos a educação enquanto prática social inserida historicamente. Com uma postura compreensiva frente às tendências pedagógicas, debruçamo-nos nesse processo analítico entendendo que as práticas educativas sofrem influências de diferentes correntes gerando confrontos e conflitos, contradições e mudanças.

O percurso analítico baseou-se na tematização (FONTOURA, 2011), onde procuramos os núcleos de sentido que focalizassem as visões de professor, do processo de ensino-aprendizagem e dos referentes formativos. Ressaltamos que não foi nosso intento traçar linhas divisórias necessárias ou ruins, mas sim clarificar as concepções e princípios do trabalho pedagógico que transversaliza o presente livro.

Assim, iniciamos com a leitura de todo o livro demarcando o que consideramos importante. A delimitação do corpus de análise deu-se com recortes de texto 
seguido de atribuição de temas conforme apareciam (visão de professor ou concepção). Posteriormente agrupamos os trechos significativos para interpretação à luz do referencial teórico.

Lemov (2011) agrupou as técnicas por temas e dividiu-as em doze capítulos. Cada capítulo se inicia com uma breve apresentação das técnicas partindo sempre do que denominamos expressões de impacto, tais como: grandes professores conseguem, métodos de excelentes professores e técnicas que professores exemplares usam.

As técnicas descritas por Lemov (2011) são sustentadas pelo aporte teórico da área empresarial, como é possível evidenciar no quadro 3:

Quadro 3 - Núcleo de sentido: perspectiva empresarial

\begin{tabular}{|l|c|}
\hline \multicolumn{1}{|c|}{ Trecho } & Capítulo \\
\hline $\begin{array}{l}\text { Depois de anos de observação e tendo lido } \\
\text { a pesquisa de Jim Collins } \text {, autor de Feitas } \\
\text { para durar e Empresas feitas para vencer, } \\
\text { dois livros altamente elogiados, eu comecei a } \\
\text { montar uma lista do que é que os professores } \\
\text { fazem, focando particularmente nas técnicas } \\
\text { que diferenciam os excelentes professores } \\
\text { não dos ruins, mas daqueles que são apenas } \\
\text { bons. (p. 19) }\end{array}$ & \\
\hline $\begin{array}{l}\text { Sim, existe uma "caixa de ferramentas" para } \\
\text { promover igualdade no desempenho escolar, } \\
\text { e eu tentei descrevê-la neste livro. (p.19) }\end{array}$ & 1 \\
\hline $\begin{array}{l}\text { Raramente os professores param para ensinar } \\
\text { a seus alunos, passo a passo, o que é um } \\
\text { comportamento de aprendizado eficaz. (p. }\end{array}$ & \\
166) & \\
\hline $\begin{array}{l}\text { Para explicar a importância da escolha do uso } \\
\text { do tempo em sala de aula. Vou-me permitir } \\
\text { fazer um pequeno paralelo com escolhas } \\
\text { financeiras. [...] A pergunta certa é se as } \\
\text { atividades que propomos em classe oferecem } \\
\text { um retorno que exceda nossa taxa mínima de } \\
\text { retorno - ou seja, dão mais aprendizagem por } \\
\text { minuto investido do que a melhor alternativa } \\
\text { de uso do tempo em classe. (p. 275) }\end{array}$ & \\
\hline
\end{tabular}

Fonte: Elaboração própria dos autores 
Pode- se inferir, que a utilização de expressões de impacto e uso de termos como eficácia, ineficiente e gerenciamento, tão frequentes no livro, assentam-se na inserção de aspectos do meio empresarial na educação. É possível visualizar neste trecho o entendimento da abordagem do tecnicismo educacional que tinha, dentre outros objetivos, o de implementar a racionalidade presente nos meios de produção no âmbito escolar (ZEICHNER, 2008). Este mesmo autor explica que as políticas neoliberais e a situação econômica global evocam tal influência mercadológica, no entanto, é necessário que o professor instrumentalize-se para um enfrentamento crítico, pois, conforme Pesce e André (2012), só desse modo os docentes poderão se sentir mais livres do poder sociopolítico e econômico e assim tomar suas próprias decisões.

Neste livro, o professor é concebido como um artesão. Para o autor, o bom ensino é uma arte na qual os grandes mestres, assim como em outras áreas - pintura, escultura, por exemplo - transformam um material no patrimônio mais valioso da sociedade. Essa visão, segundo Pesce e André (2012), assenta-se na concepção que valoriza o conhecimento em ação, sendo denominada conhecimento-em-prática ${ }^{4}$ no qual o ensino é, até certo ponto, um artesanato ainda incerto construído por meio das particularidades do cotidiano no interior das escolas e das salas de aula.

Quadro 4 - Núcleo de sentido: Ensinar é uma arte

\begin{tabular}{|l|c|}
\hline \multicolumn{1}{|c|}{ Trecho } & Capítulo \\
\hline O bom ensino é uma arte. (p.17) & 1 \\
\hline $\begin{array}{l}\text { A obra-prima depende do domínio e da } \\
\text { aplicação de habilidades fundamentais, } \\
\text { individualmente aprendidas por meio de } \\
\text { estudo diligente. (p. 17) }\end{array}$ & 1 \\
\hline $\begin{array}{l}\text { Este livro é sobre as ferramentas da arte de } \\
\text { ensinar. (p.18) }\end{array}$ & 1 \\
\hline $\begin{array}{l}\text { Sim, existe uma caixa de ferramentas para } \\
\text { promover a igualdade no desempenho escolar, }\end{array}$ & 1 \\
e eu tentei descrevê-la neste livro. (p.19) & 1 \\
\hline $\begin{array}{l}\text { É por isso que, no fim, concentra-se em } \\
\text { polir e melhorar técnicas específicas é o } \\
\text { caminho mais rápido para o sucesso, às vezes } \\
\text { até mesmo em detrimento da filosofia e da } \\
\text { estratégia. (p. 20) }\end{array}$ & \\
\hline $\begin{array}{l}\text { O caminho para o sucesso é encarar o ensino } \\
\text { como arte, ou seja, uma atividade difícil, que } \\
\text { requer refinamento e discernimento em } \\
\text { sua prática, uma dedicação artesanal e um } \\
\text { cuidadoso desenvolvimento da técnica para } \\
\text { dominá-la. (p. 329) }\end{array}$ & 12 \\
\hline
\end{tabular}

Fonte: Elaboração própria dos autores 
Percebemos que a concepção do ensino como arte constitui uma maneira de enfatizar o uso de técnicas, isto é, um passo a passo para o alcance do produto final, as aprendizagens. Tal concepção, em nosso entendimento, leva à desconsideração quanto às contribuições dos aspectos filosóficos para a educação, aspectos estes que comportam a dimensão teórica da docência. A teoria enriquece a prática e a prática enriquece a teoria, uma vez que, conforme sinalizam Pesce e André (2012), a mediação destas viabiliza a análise crítica da realidade e atribui um potencial didático à reflexão. Torna-se importante enfatizar que técnica faz parte do exercício docente possibilitando que o professor exerça o seu trabalho de promover aprendizagens ao mesmo tempo em que descortina a melhoria do ensino. Contudo é necessário refletir quanto à validade e pertinência dela para seu contexto. Como bem apontam ainda Pesce e André (2012), o professor deve se direcionar para além da mera técnica, superando a reprodução, tornando-se autor e produtor de sua ação educativa.

Lemov (2011), autor do livro analisado, propõe atividades reflexivas ao final de cada capítulo, possibilitando aos professores relacionar sua prática em sala de aula com as técnicas explicitadas. Apresentamos no quadro 5 alguns exemplos das atividades reflexivas sugeridas no livro como forma de evidenciar nossa constatação:

Quadro 5 - Núcleo de sentido: Referente formativo reflexivo

\begin{tabular}{|l|c|}
\hline \multicolumn{1}{|c|}{ Trecho } & Capítulo \\
\hline $\begin{array}{l}\text { As atividades abaixo ajudarão você a pensar e } \\
\text { praticar as técnicas do capítulo: }\end{array}$ & 1 \\
O capítulo apresentou cinco técnicas para \\
elevar as expectativas acadêmicas na sua \\
classe: Sem escapatória, Certo é certo, \\
Puxe mais, Boa expressão e Sem desculpas. \\
Qual delas será mais intuitiva para você \\
implementar em sua classe? Qual será a mais \\
difícil e o que a torna difícil? (p.73) \\
$\begin{array}{l}\text { Escolha uma expectativa de aprendizagem } \\
\text { do seu município ou estado. Antes de } \\
\text { analisá-la, tente adivinhar quantos objetivos } \\
\text { você realmente precisaria para que seus } \\
\text { alunos a dominassem. Agora, divida essa } \\
\text { expectativa em uma série de objetivos viáveis } \\
\text { e mensuráveis, que tenham uma sequência } \\
\text { lógica, da introdução da ideia ao domínio } \\
\text { completo do assunto. Em seguida tente } \\
\text { aumentar ou diminuir o número de dias } \\
\text { letivos disponíveis em 20\%. Como isso muda } \\
\text { seus objetivos? (p.88) }\end{array}$
\end{tabular}




\begin{tabular}{|l|l|}
\hline $\begin{array}{l}\text { Pegue um plano de aula que você aplicará } \\
\text { em breve e identifique três momentos em } \\
\text { que seria bom usar De surpresa. Escreva suas } \\
\text { perguntas no próprio plano de aula. Faça } \\
\text { algumas anotações sobre quais alunos você }\end{array}$ & 5 \\
vai chamar De surpresa. (p.162) & \\
\hline $\begin{array}{l}\text { Considere quais traços comportamentais } \\
\text { específicos você mais quer que seus alunos } \\
\text { mostrem em sua aula. Para cada um, escreva } \\
\text { três ou quatro roteiros que você pode usar } \\
\text { para reforçá-los com elogio preciso. (p.243) }\end{array}$ & 7 \\
\hline
\end{tabular}

Fonte: Elaboração própria dos autores

Podemos evidenciar nessas propostas uma dinâmica que centra-se no que Zeichner (2008) denomina de slogan da reflexão, uma vez que o incentivo reflexivo, nesta perspectiva, reside em reproduzir um método de ensino supostamente mais eficaz para elevar o desempenho dos alunos, ao invés de possibilitar um enfrentamento crítico com a realidade. Para Zeichner (2008), a reflexão sobre o ensino que possibilite realmente o desenvolvimento profissional deve tornar os professores mais conscientes das dimensões moral e ética levando-os a exercerem um papel ativo na formulação das finalidades do seu trabalho.

Inferimos que o conceito de reflexão expresso nas propostas do livro tem as técnicas e métodos de ensino como essência, direcionando um pensar individual dos professores sobre seu próprio ensino. Esse viés individualista, segundo Zeichner (2008), anula a possibilidade de transformação dos aspectos estruturais do trabalho docente, pois são desconsideradas as condições sociais da educação escolar. Entendemos que as dinâmicas reflexivas precisam ser concebidas enquanto um processo que proporcione pensar as escolhas que são feitas em sala de aula, ou a fazer, adaptando as práticas de ensino no encontro com as necessidades dos alunos.

O processo de ensino-aprendizagem é assumido no livro enquanto instrução permeada por estímulos e por respostas esperadas em cada técnica. Para o autor, o ensino eficaz deve oferecer ao aluno a oportunidade de praticar e praticar. Discordamos dessa posição, pois apreendemos que o processo de ensino-aprendizagem ancorado na repetição promove uma prática alienante, que mata nos educandos a curiosidade, o espírito investigador e a criatividade (FONTOURA, PIERRO, CHAVES, 2011), além de destituir do próprio docente a sua capacidade criadora, transformando-o em um mero executor burocrático. Selecionamos no quadro 6, alguns trechos para clarificar nossa constatação: 
Quadro 6 - Núcleo de sentido: Ensino baseado em estímulo/resposta/repetição

\begin{tabular}{|c|c|}
\hline Trecho & Capítulo \\
\hline $\begin{array}{l}\text { É repetição. É mais uma vez - para cirurgias } \\
\text { complexas, para bater a bola de beisebol, } \\
\text { resolver problemas de matemática e escrever } \\
\text { corretamente. (p.124) }\end{array}$ & 3 \\
\hline $\begin{array}{l}\text { Discurso positivo corrige e orienta } \\
\text { comportamentos conforme seis regras } \\
\text { seguintes: viva o agora, pressuponha o } \\
\text { melhor, permita anonimato, gere energia e } \\
\text { descrições positivas, desafio, fale aspirações e } \\
\text { expectativas. (p. } 225 \text { ) }\end{array}$ & 7 \\
\hline $\begin{array}{l}\text { Esses métodos permitem reforçar tanto o } \\
\text { automatismo como a compreensão, de um } \\
\text { jeito que a maioria dos alunos vai achar } \\
\text { divertida. (p.296) }\end{array}$ & 11 \\
\hline
\end{tabular}

Fonte: Elaboração própria dos autores

Nas práticas educativas é possível reconhecer, como bem apontam Fontoura, Pierro e Chaves (2011), diferentes correntes e tendências pedagógicas. E o livro o qual analisamos não escapa dessa percepção. Nos trechos acima sinalizados fica clara a abordagem tradicional e comportamental/tecnicista com os aspectos da repetição e dos estímulos /respostas.

Identificamos no livro que a relação professor-aluno deve se pautar no alinhamento com os métodos de instrução, métodos esses que permitam "manter regularmente altas taxas de potencialização nas atividades” (LEMOV, 2011, p.277). O professor é concebido enquanto um executor, isto é, aquele que emprega as metodologias que os melhores de sua profissão utilizam, e os estudantes, aqueles que somente cumprem comandos. No quadro 7 evidenciamos essa constatação.

Quadro 7 - Núcleo de sentido: relação professor-aluno

\begin{tabular}{|l|c|}
\hline \multicolumn{1}{|c|}{ Trecho } & Capítulo \\
\hline $\begin{array}{l}\text { Em resumo: seus alunos precisam saber que } \\
\text { tipo de resposta você quer. (p.146) }\end{array}$ & 4 \\
\hline $\begin{array}{l}\text { Mas qualquer que seja sua escolha, você deve } \\
\text { levar a sério os comandos. (p.190) }\end{array}$ & 6 \\
\hline $\begin{array}{l}\text { Os alunos seguem as orientações sem nem } \\
\text { parecer pensar sobre isso. Assim, a cultura da } \\
\text { observância é ao mesmo tempo positiva e - } \\
\text { mais importante - invisível. (p.188) }\end{array}$ & 6 \\
\hline
\end{tabular}




\begin{tabular}{|l|c|}
\hline $\begin{array}{l}\text { A escola é um espaço de aprendizado para os } \\
\text { alunos; eles devem ser capazes de aprender } \\
\text { como se comportar. (p. 239) }\end{array}$ & 7 \\
\hline $\begin{array}{l}\text { Disciplinar-se para usar a técnica 'Uma de } \\
\text { cada vez', especialmente nos momentos em } \\
\text { que você está mais envolvido [...]. (p. 257) }\end{array}$ & 9 \\
\hline
\end{tabular}

Fonte: Elaboração própria dos autores

Identificamos, nesse caso, a relação professor-aluno baseada na perspectiva comportamental, uma vez que a comunicação entre o docente e estudantes é marcada por uma estruturação com vistas ao reforço do que será trabalhado. A abordagem tecnicista ou comportamental, explicam Fontoura, Pierro e Chaves (2011), tem como marco na relação professor-alunos a transmissão de determinado conhecimento de modo estruturado, numa instrução que reforce um comportamento final esperado.

Práticas pedagógicas assentadas na execução de comandos, como sinalizada na tabela 7, esvaziam de sentido o processo de formação de nossos alunos; o conhecimento a ser trabalhado limita-se à transmissão, por parte do professor, e à retenção da parte dos alunos. Tais práticas seguem em posição contrária ao que pesquisadores do campo educacional defendem há tempos, que o ensino deve promover a construção de conhecimentos e a compreensão dos estudantes perante o mundo que o rodeia.

Comungamos com Zeichner (2008) quando afirma que a superação do modelo transmissivo dar-se-á pelo reconhecimento dos professores de seu poder decisório, logo, precisamos nos certificar que os professores sabem como tomar decisões, no dia-a-dia, que não limitem as chances de vida de seus alunos; que eles tomem decisões com uma consciência maior das possíveis consequências políticas que as diferentes escolhas podem ter.

As técnicas apresentadas por Lemov nos doze capítulos são permeadas por estímulos e a produção de respostas consideradas adequadas. Destaca ao leitor como aspecto importante para obtenção de melhores resultados, o estar alinhado à instrução, respeitar a técnica em sua sequência e a necessidade de repetição. Esse fato nos leva a inferir sobre certos elementos que levam a um comportamento condicionado.

Com este movimento analítico no qual buscamos identificar a visão de professor, concepção de ensino-aprendizagem e os referentes formativos no livro "Aula nota 10- quarenta e nove técnicas para ser um professor campeão de audiência", encontramos a visão do professor como um artesão, a concepção de ensino aprendizagem assentada no viés tradicional e comportamentalista e os referentes formativos baseados numa perspectiva transmissiva.

A percepção dos professores como artesãos descortina um entendimento de que estes profissionais trabalham sozinhos em classe acumulando saberes, como ex- 
plica Garcia (2010), ao se legitimar o modelo do professor como artesão, isto é, aquele que é individualista e sensível ao contexto, implica a visão de que trabalham, aprendem e desenvolvem-se na maior parte sozinhos ou por suas interações com os alunos.

Esse olhar desconsidera o caráter coletivo do trabalho escolar privando os professores de enriquecerem suas ações através da interação com seus companheiros. É preciso uma compreensão de que a participação conjunta e integrada dos professores, coordenadores, diretores e seus alunos criam um ambiente que potencializa a aprendizagem além de fortalecer os docentes para o enfrentamento dos desafios cotidianos.

Identificamos uma concepção de ensino-aprendizagem assentada no viés tradicional e comportamentalista. As técnicas são demarcadas como passos a serem seguidos num itinerário composto de intensa exposição oral tendo em vista a repetição, reforço de comportamentos e controle.

Fontoura, Pierro e Chaves (2011) explicam que cada tendência pedagógica, fruto de movimentos filosóficos, políticos e sociais, possui características internas predominantes. Assim sendo, nas tendências tradicionais e comportamentais, tendências estas que identificamos na análise do livro, destacam as autoras, há predominância do ensino verbalista, marcado pela instrução individualizada com perspectivas de controle, reforço, objetivando um comportamento final.

Evidenciamos tais características no decorrer do livro, já que em cada técnica o autor enfatiza a importância da repetição, pois em suas palavras, nunca se aprende na primeira vez; destaca também a necessidade de atenção por parte dos professores perante seus discursos que devem, sobretudo, orientar comportamentos e reforçar automatismos. Assumimos que precisamos provocar rupturas com o ensino centrado na verbalização desvinculada de contexto e de métodos que buscam tão somente reforçar habilidades e comportamentos. Tornam-se necessárias situações de aprendizagens que promovam, a partir da apropriação de conhecimentos, compreensão e reflexão com criticidade e criatividade.

No que tange aos referentes formativos (ANDRÉ, 2015), isto é, os aspectos considerados importantes numa ação de formação, pudemos perceber um direcionamento à reflexão esvaziado do seu real sentido, pois "não são voltadas ao fortalecimento da postura ética ou o profissionalismo docente"(ANDRÉ, 2015, p.37).

Foi possível identificar reflexões simplistas voltadas para pensar a utilização das técnicas no dia a dia docente. Acreditamos que as dinâmicas reflexivas precisam instrumentalizar os professores a melhorarem o seu ensino, o estar na profissão através da construção de novos conhecimentos e do questionamento dos métodos já existentes. Para isso, explicam Pesce e André (2012), é necessário oferecer aos professores a possibilidade de assumirem a realidade escolar como objetivo de suas indagações.

Perpassando os focos elencados para análise do livro (visão de professor, concepção de ensino-aprendizagem e os referentes formativos) estava a relação professor-aluno. Segundo Fontoura, Pierro e Chaves (2011), tal relação encerra um conjunto de componentes que integram, dentre outros, o preparo do professor, o plano, o 
material didático, a sua postura como pessoa e o seu compromisso social visando à construção de sentido na dinâmica do processo de ensinar e aprender.

Conforme explicitado na tabela 7 , foi possível perceber a relação professor-aluno num movimento de controle, objetivando ajustes de comportamentos. Do professor era esperado disciplina e seriedade para o cumprimento dos comandos expressos nas técnicas e para os alunos havia uma expectativa de que seguissem as orientações e respondessem conforme o traçado do conteúdo transmitido.

Em contraposição, afirmamos que a relação educativa exige muito mais do que o domínio de técnicas e ajustes comportamentais, pois o aluno é um sujeito ativo que em suas atividades no processo de conhecer vai dando sentido ao que sabe e segue aprendendo, e o professor, um profissional que desafia, questiona e sustenta esse outro colocado em situação de aprendiz. Portanto, os bons resultados nessa relação são resultados "das capacidades técnicas, de conteúdo e de relacionamento, em um conjunto que funcione para motivar alunos a se esforçarem e aprenderem mais e melhor". (FONTOURA; PIERRO; CHAVES, 2011, p.120).

Da presente análise, concluímos que as técnicas presentes no livro pautamse na abordagem comportamental/tecnicista, pois são explicitadas como instruções que devem ser seguidas paulatinamente para o alcance dos resultados, não comungando com as perspectivas atuais de ensino-aprendizagem que buscam a autonomia docente e sua autoria na dinâmica de ensinar e aprender. Com André e Pesce (2012) reforçamos nossa visão de que os professores não podem ser concebidos como consumidores acríticos, mas sim construtores de conhecimentos que no dia a dia de suas práticas encontram caminhos para desenvolver suas próprias técnicas.

Entendemos, a partir da conjugação dos resultados, que há a presença da concepção tradicional do professor distinguido entre aquele que executa e que pensa. Nesta perspectiva defendemos a necessidade de uma postura docente não aplicacionista, e sim crítica, para sermos capazes de a partir das técnicas expressas no livro, tomar nossas próprias decisões, com conhecimento, competência e criatividade.

\section{Referências}

ANDRÉ, M. E. D. Políticas de formação continuada e de inserção à docência no Brasil. Educação Unisinos, v.19, n.01,jan./abr. 2015.

BIZZO, N. M. V. Ciências: Fácil ou Difícil? 1.ed. São Paulo: Editora Biruta, 2009.

PESCE, M. K.; ANDRÉ, M. E. D. Formação do professor pesquisador na perspectiva do professor formador. Formação Docente, Belo Horizonte,v. 04, n. 07, p. 39-50, jul./dez. 2012.

FONTOURA, H. A. Tematização como proposta de análise de dados na pesquisa qualitativa. IN: FONTOURA, H. A. (Org) Formação de professores e diversidades culturais: múltiplos olhares em pesquisa. Niterói: Intertexto, 2011.

FONTOURA, H. A.; PIERRO, G. M.S.; CHAVES, I. M. A. B. Didática: do ofício e da arte de ensinar. Niterói: Intertexto, 2011.

GARCIA, C. M.O professor iniciante, a prática pedagógica e o sentido da experiência. Formação Docente: Belo Horizonte, v.02, n.03, p.11-49, ago./dez. 2010. 
LEMOV, D. Aula nota 10 - quarenta e nove técnicas para ser um professor campeão de audiência. São Paulo: Da Boa Prosa: Fundação Lemann, 2011.

ZEICHNER, K. Uma análise crítica sobre a "reflexão" como conceito estruturante na formação docente. Edu. Soc., Campinas, v.29, n.103, p. 535-554, maio/ago. 2008.

Notas

${ }^{1}$ Não há no livro a tradução do termo para a língua portuguesa.

${ }^{2} \mathrm{O}$ autor não menciona, por extenso, o significado da sigla SWA.

${ }^{3}$ Jim Collins é um consultor americano conhecido por seus estudos sobre gestão e negócios.

${ }^{4}$ Knowledge in practice, apud Cochran-Smith e Lytle (1999).

* Doutor em Ciências na área de concentração Ensino formal em Biociências e Saúde pela Fundação Oswaldo Cruz, Rio de Janeiro, Rio de Janeiro, Brasil.

** Professora doutora do Departamento de Educação da Faculdade de Formação de Professores da Universidade do Estado do Rio de Janeiro, São Gonçalo, Rio de Janeiro, Brasil.

\section{Correspondência}

Helena Amaral da Fontoura - Universidade do Estado do Rio de Janeiro, Faculdade de Formação de Professores. Rua Francisco Portela, 1470, Patronato. CEP: 24435005. São Gonçalo, Rio de Janeiro, Brasil.

E-mail: figueiras.tiago@gmail.com - helenaf@uerj.br

Recebido em 02 de agosto de 2016

Aprovado em 05 de fevereiro de 2018 